online travel and e-following contributing similarly. Another enormous section in online business is portable/DTH energize with about 1 million exchanges day by day by administrator sites. Another part in webbased business is online pharmaceutical, offering reciprocal and option solution or physician endorsed drug on the web. There are no devoted online drug store laws in India and it is allowable to offer physician endorsed medication online with an authentic permit. Online offers of extravagance items like gems likewise expanded throughout the years. The vast majority of the retail marks have additionally begun going into the market and they expect no less than $20 \%$ deals through online in next $2-3$ years.

\section{REVIEW OF LITRATURE}

Electronic business, normally composed as web based business or web based business, is the exchanging or assistance of exchanging items or administrations utilizing PC systems, for example, the web or online interpersonal organizations Electronic trade draws on advances, for example, versatile trade, electronic assets exchange, store network administration, web showcasing, online exchange handling, electronic information exchange (EDI), stock administration framework and mechanized information gathering frameworks. Present day electronic business normally utilizes the internet for no less than one a player in the exchange's life cycle despite the fact that it might likewise utilize different innovations, for example,

$>$ Online shopping sites for retail deals direct to consumers

$>$ Providing or taking an interest in online commercial centers, which prepare outsider business-to-buyer or purchaser to-shopper sales

$>$ Business to business purchasing and selling

$>$ Gathering and utilizing statistic information through web contacts and social media

$>$ Business-to-business (B2B) electronic information trade

$>$ Marketing to imminent and built up clients by email or fax (for instance, with news letters)

$>$ Engaging in pre-tail for propelling new items and services

$>$ Online money related trades for cash trades or exchanging purposes.

General Inclination, In 2010, the United Kingdom had the greatest web based business showcase on the planet when measured by the sum spent per capita starting at 2013, the Czech Republic was the European nation where web based business conveys the greatest commitment to the undertakings' aggregate income. Just about a quarter (24\%) of the nation's aggregate turnover is created by means of the online channel Among developing economies, China's web based business nearness keeps on extending each year. With 668 million web clients, China's Internet shopping deals came to $\$ 253$ billion in the principal half of 2015 , representing $10 \%$ of aggregate Chinese purchaser retail deals in a similar period. The Chinese retailers have possessed the capacity to help customers feel more great shopping on the web. Web based business exchanges amongst China and different nations expanded 32\% to 2.3 trillion Yuan (\$375.8 billion) in 2012 and represented $9.6 \%$ of China's aggregate worldwide exchange 2013, Alibaba had a web based business piece of the overall industry of $80 \%$ in China In 2014, there were 600 million Internet clients in China (twice the same number of than in the US), making it the world's greatest online market. China is additionally the biggest web based business advertise on the planet by estimation of offers, with an expected US\$899 billion in 2016.

\section{EFFECT ON SUPPLY CHAIN MANAGEMENT :}

For quite a while, organizations had been beset by the hole between the advantages which production network innovation has and the answers for convey those advantages. In any case, the rise of online business has given a more viable and viable method for conveying the advantages of the new store network innovations. Web based business has the ability to coordinate all between organization and intra-organization capacities, implying that the three streams (physical stream, budgetary stream and data stream) of the store network could be likewise influenced by online business. The affections on physical streams enhanced the method for item and stock development level for organizations. For the data streams, web based business streamlined the limit of data preparing than organizations used to have, and for the money related streams, internet business enables organizations to have more effective installment and settlement arrangements. Also, web based business has a more refined level of effect on supply chains:

Firstly, the execution hole will be dispensed with since organizations can distinguish holes between various levels of supply chains by electronic methods for arrangements;

Secondly, subsequently of online business rise, new abilities such actualizing ERP frameworks, similar to SAP ERP, have helped organizations to oversee 
operations with clients and providers. However these new abilities are as yet not completely abused.

Thirdly, innovation organizations would continue contributing on new web based business programming arrangements as they are expecting speculation return.

Fourthly, web based business would tackle numerous parts of issues that organizations may feel hard to adapt to, for example, political boundaries or cross country changes.

At last, web based business gives organizations a more proficient and successful approach to team up with each other inside the inventory network. Alongside the web based business and its one of a kind appeal that has seemed step by step, virtual venture, virtual bank, arrange promoting, web based shopping, installment and publicizing, such this new vocabulary which is inconceivable and now has progressed toward becoming as recognizable to individuals. This mirrors the online business has tremendous effect on the economy and society from the opposite side. For example, B2B is a quickly developing business on the planet that prompts bring down cost and afterward enhances the monetary productivity and furthermore bring along the development of employment.

1) The web-based business has changed the relative significance of time, however as the mainstays of pointer of the nation's financial express that the significance of time ought not be ignored.

2) The online business offers the shopper or undertaking different data they require, making data into aggregate straightforwardness, will constrain endeavor never again can utilize the method of space or notice to raise their aggressive edge. Moreover, in principle, culminate rivalry between the purchaser power and industry will boost social welfare.

3) Truth be told, amid the financial movement before, substantial endeavor much of the time has favorable position of data asset, and accordingly to the detriment of customers.

These days, the straightforward and constant data ensures the privileges of shoppers, on the grounds that the purchasers can utilize web to choose the portfolio to the event of themselves.

\section{Objectives of Study}

1) To know the current circumstance of online business in India.
2) How the demonetization help the web based business in future.

\section{Methodology}

This paper is completely done by optional information, gathered from sources like Research offices, sites and news papers. The primary motivation behind this is to give a look of Demonetization and its consequences for web based business.

\section{Findings}

Regardless of the amazing numbers, incredulity around internet business is as yet alive -and in light of current circumstances. The Indian online business industry is still a long way from making benefit. Actually, Flipkart was downgraded by 27 percent by Morgan Stanley and later another 15 percent by $\mathrm{T}$ Rowe Price as of late. They are esteemed at under $\$ 10$ billion, from $\$ 15$ billion in 2015. Half a month back, online eatery find stage Zomato was degraded by 50 percent, to $\$ 500$ million, by HSBC. As much as these organizations say there is no subsidizing crunch, it is an open mystery that most biggies are battling. A Live mint report as of late expressed that Flip kart and Snap bargain in actuality are dormant and seeing a fall in deals. The last is likewise downsizing provincial operations now. India is a gigantic E-Commerce commercial center now with each age assemble serenely executing on the web - all the more regularly favoring shopping on the web as opposed to going by disconnected stores for a greater range of decisions and offers. The West shops online $10 \mathrm{X}$ more than India, yet then India has the world's second biggest number of advanced mobile phones and growing E-Commerce industry is developing at an amazing rate in India and is relied upon to represent $1.61 \%$ of the worldwide GDP by 2018 . The AsiaPacific locale is at present the biggest E-Commerce advertise on the planet, outperforming Europe. While China keeps on driving the race, the Indian ECommerce Industry isn't a long ways behind. As indicated by a report by Forrester, India is set to end up plainly the quickest developing business sector in the Asia-Pacific locale with a normal development rate of more than 57\% between 2012-2016. To better comprehend the Indian market, $100+$ retailer customers, through $1.4+$ million buys, from more than $2+$ million exchanges. A first of its kind in India, this review is extraordinary in its discoveries about the blasting Indian E-Commerce industry. Online advertisers of each size are profiting from these discoveries. 


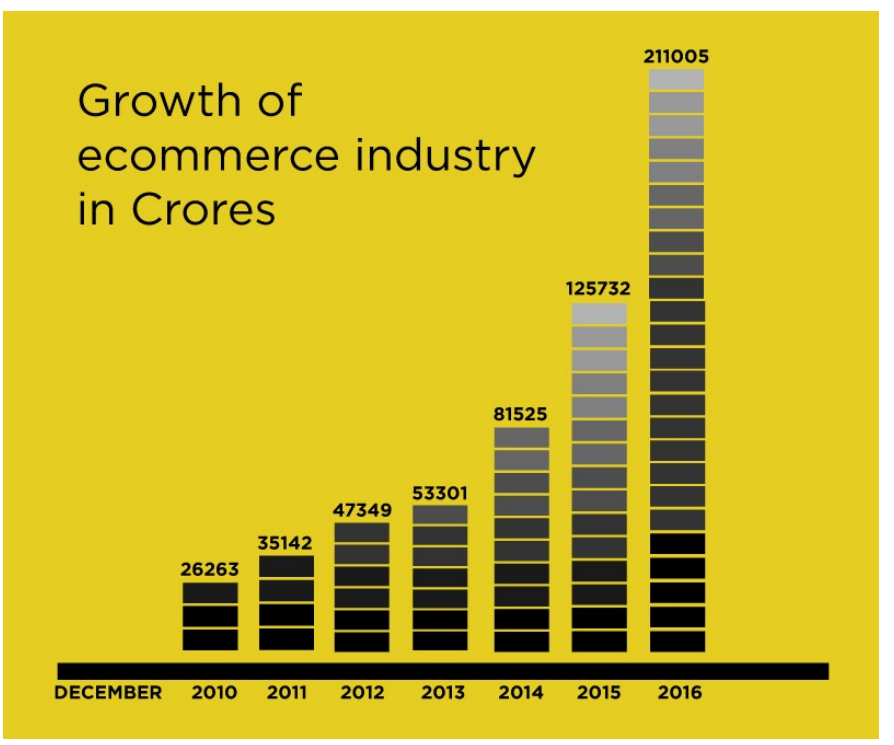

Figure: 1 Latest study by the Internet and Mobile Association of India (IAMAI)

\section{AFFECT OF DEMONETIZATION ON E- COMMERCE}

\section{Demonetization:}

The objective of the demonetization move in India is to make the economy more grounded and dispense with the parallel money economy which is unaccounted and untaxed. While this can affect the GDP contrarily temporarily, it ought to have positive long haul results. For internet business organizations, which as of now have a computerized installments framework set up, it ought to prompt higher online installment and in the long run dispense with the agonizing money down alternative. Be that as it may, for the time being, witness a decrease in GMV from India as the economy acclimates to the "new normal".

\section{Reduction in cash on delivery}

Cash-on-delivery (COD) is considered as a vital insidiousness in the Indian internet business showcase. While it helps offers of online organizations, it hinders their money streams and makes it hard proportional operations. There are a few extra costs required with this installment technique and the danger of profits and robberies with this type of installment are higher. The current government push towards a cashless economy will empower more online installments and lessen the aggregate share of COD in internet business deals from the present high of about $80 \%$ of aggregate exchanges. This ought to help internet business organizations to decrease overhead expenses and different dangers related with the COD model. In any case, in an area where a little segment of the populace possesses credit or check cards ( $12 \%$ as indicated by a 2014 report), a move towards a computerized installments will be troublesome and can affect incomes fundamentally in the short term.

The current circumstance in India is the precise level shape for the advancement of internet business or online business. Demonetization prompts individuals make utilization of net managing an account for their day today life. This is the great open door for the internet business organizations to make themselves more faithful to clients whether the exchange is little or enormous. Formation of trust in client is exceptionally troublesome in today's business, once he get happy with the products and ventures given by the organization beginning from the request booking to protected and exact conveyance client will get or wind up noticeably faithful to that. In one way the administration is additionally urge general society to utilize net saving money by method for doing the online exchanges more in day today life. Telecom segment is presently needs to think the rustic region more to get utilization of online deal or buys, at the same time the managing an account frameworks to give the net saving money offices to country individuals to get touch with the most recent innovation of web based keeping money or marketing.

\section{Boon of Indian E-commerce Industry}

Annual extra cash per family to develop by over two times by 2015

$>$ Discretionary spending anticipated that would shape a noteworthy segment of use in India

$>$ Proliferation expected in the offers of PCs, tablets and shrewd phones

$>$ More Indians expanding time spent online

$>$ Probability of development in web client base, reflecting that of the voice client base

$>$ Volume and normal estimation of exchanges higher for MasterCard's than charge cards

$>$ Increase in the quantity of installment options

\section{Bane of Indian E-commerce Industry}

$>$ Low normal broadband speed and level normal web speed reason for concern

$>$ Online installment scene defaced by low infiltration of credit and charge cards

$>$ High disappointment rate of online installment transactions.

\section{Challenges for E-Commerce}


The extraordinary development of the web based business area is joined by certain challenges:

$>$ Absence of internet business laws

$>$ Low section obstructions prompting lessened focused advantages

$>$ Rapidly changing business models

$>$ Urban phenomenon

$>$ Shortage of manpower.

\section{Opportunities for the e-commerce.}

$>$ Reduction of money transactions in all sectors.

$>$ Improvement of Net banking facilities across the country.

$>$ Implementation of demonetization policy.

$>$ Government policies on banking and financial sectors.

Now the point will come and stop at the situation how the government will solve the problem and implement the proper system to regulate the country economy and social life of people. Using of net banking and doing online transaction through internet and mobiles is not difficult for students or who have some minimum knowledge of doing transactions. Coming to point of rural area in which 83.3 crore people are staying and only 37.7 crore are in urban, facilities which reach the rural area is less compare to urban area where the population is less than the half of rural population. Government should think of telecommunications and banking sectors to invest the funds to reach the maximum people.

Banking sector should create the awareness of using internet banking and ATM's to get use of service across the country where ever they travel and minimize the high failures of online transactions. After the confirmation of order the e-commerce companies should think of proper delivery of goods with accurate tracking system for that we should set up a tracking order system from order to delivery. It will leads to customer satisfaction then the consumer trust the product or services offer by the company, after regular purchases he will become loyal to particular brand or product/ company.

\section{Conclusion}

E-commerce is not a new industry, technically speaking, but it is creating a new economic model. Most people agree that e-commerce will positively impact economic society in the future, but in its early stages its impacts are difficult to gauge. Some have noted that ecommerce is a sort of incorporeal revolution. E- commerce has numerous social benefits: one, the cost of running an e-commerce business is very low when compared with running a physical store; two, there is no rent to pay on expensive premises; and three, business processes are simplified and less man-hours are required to run a typical business smoothly. In the area of law, education, culture and also policy, e-commerce will continue to rise in impact. E-commerce will truly take human beings into the information society. Demonetization will help the e-commerce industry and insist or encourage the people to use more cash less transactions in day to day life, so that the people need not carry the money in currency form for any purchases like Hair oil to shoe from Head to legs of human needs. This will helps the banking sector to expand the business to rural areas quickly and do the more business to reach the general public for their regular activities. Lower inflation, lower interest rates and lower budget deficits are likely to be the long term positive macroeconomic effects of the move, which should stimulate economic growth and benefit businesses in the region. However, as the country undergoes this huge transformation from a cash dominant economy to a near cashless economy. This move will definitely bring about a sea of change in the way transactions are done in India. And help strengthen the economy by wiping out black money and fake notes. While e-commerce companies that see a huge chunk of payments happening through Cash on Delivery mode will face some challenges in the initial few days, in the long run this move will only bring about positive changes.

\section{References}

1) http://www.indianeconomy.net/splclassroom/309/w hat- are-the-impacts-of-demonitisation-on-indianeconomy/\#sthash.wIhn787q.dpuf

2) https://en.wikipedia.org/wiki/2016_Indian_banknot e_de monetisation

3) http://www.moneycontrol.com/news/economy/impa ct- analysisdemonitizationindia 8044821.html?utm source $=$ ref article

4) http://www.business-standard.com/article/economypolicy/five-likely-effects-of-demonetisation-oneconomy-116110901411_1.html

5) http://economictimes.indiatimes.com/articleshow $/ 5$ 5348597.cms?utm_source $=$ contentofinterest\&utm medium $=$ text\&utm_campaign $=$ cppst

6) http://www.financialexpress.com/economy/historyof-demonetisation-when-morarji-desai-governmentceased-rs-500-rs-1000-and-rs 